\title{
Changes in copepod distributions associated with increased turbulence from wind stress
}

\author{
L. S. Incze ${ }^{1, *}$, D. Hebert ${ }^{2}$, N. Wolff ${ }^{1}$, N. Oakey ${ }^{3}$, D. Dye $^{1}$ \\ ${ }^{1}$ Bigelow Laboratory for Ocean Sciences, West Boothbay Harbor, Maine 04575, USA \\ ${ }^{2}$ Graduate School of Oceanography, University of Rhode Island, Kingston, Rhode Island 02882, USA \\ ${ }^{3}$ Bedford Institute of Oceanography, Dartmouth, Nova Scotia B2Y 4A2, Canada
}

\begin{abstract}
Vertical profiles of turbulent kinetic energy dissipation rate $(\varepsilon)$, current velocity, temperature, salinity, chlorophyll fluorescence, and copepods were sampled for $4 \mathrm{~d}$ at an anchor station on the southern flank of Georges Bank when the water column was stratified in early June 1995. Copepodite stages of Temora spp., Oithona spp., Pseudocalanus spp., and Calanus finmarchicus, and all of their naupliar stages except for Temora spp., were found deeper in the water column when turbulent dissipation rates in the surface mixed layer increased in response to increasing wind stress. Taxa that initially occurred at the bottom of the surface mixed layer at 10 to $15 \mathrm{~m}$ depth $\left(\varepsilon \leq 10^{-8} \mathrm{~W}\right.$ $\mathrm{kg}^{-1}$ ) before the wind event were located in the pycnocline at 20 to $25 \mathrm{~m}$ depth when dissipation rates at $10 \mathrm{~m}$ increased up to $10^{-6} \mathrm{~W} \mathrm{~kg}^{-1}$. Dissipation rates in the pycnocline were similar to those experienced at shallower depths before the wind event. After passage of the wind event and with relaxation of dissipation rates in the surface layer, all stages returned to prior depths above the pycnocline. Temora spp. nauplii did not change depth during this period. Our results indicate that turbulence from a moderate wind event can influence the vertical distribution of copepods in the surface mixed layer. Changes in the vertical distribution of copepods can impact trophic interactions, and movements related to turbulence would affect the application of turbulence theory to encounter and feeding rates.
\end{abstract}

KEY WORDS: Turbulence · Zooplankton · Vertical distribution · Vertical migration · Chlorophyll maximum $\cdot$ Stratification $\cdot$ Mixing

\section{INTRODUCTION}

Pelagic environments are characterized by vertical changes in light, temperature, turbulence, transport, food and predators. These conditions vary non-uniformly in space and time. As a result, zooplankton face a highly variable environment in which to feed, mate, avoid predators and recruit to satisfactory habitats. The vertical distribution patterns and movements of zooplankton reflect evolved strategies for dealing with these conditions. In turn, the vertical distributions affect other processes, such as feeding by planktivorous fishes. Despite the importance of vertical position to vital rate functions (feeding, respiration, reproduc-

*E-mail: lincze@bigelow.org tion) and trophic interactions, only a few of the possible environmental stimuli and corresponding zooplankton responses are known well enough to be predictive. For example, in the past, different studies provided conflicting evidence about the prevailing depth distribution patterns of species and diel patterns of vertical migrations (DVM: Hays et al. 1997). Recent findings have shown substantial plasticity in DVM patterns when certain predators are present (Neill 1990, 1992, Ohman 1990, Bollens \& Stearns 1992, Frost \& Bollens 1992). This accounts for some of the prior conflicting data and suggests that the risk of predation weighs heavily among the factors influencing this behavior. Turbulent mixing also affects zooplankton behavior (Costello et al. 1990, Saiz \& Alcaraz 1992, Saiz 1994) and has been associated with changes in zooplankton 
vertical distributions (Buckley \& Lough 1987, Mackas et al. 1993, Haury et al. 1990,1992, Incze et al. 1990, Checkley et al. 1992, Lagadeuc et al. 1997). Moreover, small-scale turbulence may directly affect feeding rates of zooplankton (Yamazaki et al. 1991, Kiørboe \& Saiz 1995, Saiz \& Kiørboe 1995, Osborn 1996) and larval fish (Dower et al. 1997, MacKenzie \& Kiørboe $1995,2000)$ through changes in shear velocities and modifications of feeding and searching behavior (Saiz 1994, Mackenzie \& Kiørboe 1995). While the intensity of turbulence in the upper ocean is strongly correlated with the wind stress (Oakey \& Elliott 1982, Mackenzie \& Leggett 1991), the vertical structure of small-scale turbulence may be quite complicated (Denman \& Gargett 1988, Gargett 1989). This places limits on the usefulness of proxy variables for estimating turbulence at discrete depths and inferring behavioral and other rate functions for the resident plankton (Mullin et al. 1985, Yamazaki \& Osborn 1988, Simpson et al. 1996, Gargett 1997).

Since turbulence is ubiquitous and highly variable, a better understanding of zooplankton responses to changing turbulence, as well as any preferences for certain ranges, is needed in order to predict and interpret distributions and their biological consequences. At the same time, better information is needed concerning the structure of turbulence within the surface mixed layer and the pycnocline, where many of the biological interactions take place. In this paper we examine the relationship between measured, in situ turbulence and the vertical position of several abundant copepod taxa on the stratified southern flank of Georges Bank, off the northeastern coast of the USA.

Georges Bank, historically noted for its high fisheries production (Brown 1987), is approximately $300 \mathrm{~km}$ long $\times 175 \mathrm{~km}$ wide. The crest of the bank $(<50 \mathrm{~m}$ deep) remains mixed throughout the year by the combined energy of winds and strong tidal currents (Horne et al. 1996), while at depths $>60 \mathrm{~m}$ the water column becomes stratified during warm months of the year. Stratification begins in May and lasts until fall, when it is eroded by seasonal surface cooling and increased wind mixing (Flagg 1987). Residual circulation is clockwise around the bank and is well developed during the stratified period (Butman et al. 1987, Limeburner \& Beardsley 1996). The physics and biology of the bank are being investigated through the current US and Canadian GLOBEC programs (Wiebe et al. 2001), of which this study is a part.

\section{MATERIALS AND METHODS}

Data were collected on the southern flank of Georges Bank from 11 to 15 June 1995. The vessel was an- chored at $40.86^{\circ} \mathrm{N}, 67.54^{\circ} \mathrm{W}$ throughout the sampling period in a nominal depth of $75 \mathrm{~m}$ of water (Fig. 1).

Microstructure measurements of temperature, salinity and velocity were made with a tethered free-fall profiler (EPSONDE: Oakey 1988) that was deployed from the stern of the vessel and descended at 0.5 to $1 \mathrm{~m} \mathrm{~s}^{-1}$ until it hit the bottom. The sensor package was recessed $5 \mathrm{~cm}$ behind a circular, $30 \mathrm{~cm}$-diameter, stainless steel lander. The tether was a kevlar multiconductor payed out loosely ahead of the falling profiler and used for data transmission and instrument recovery. Velocity fluctuations were measured by 2 shear probes sampling at $256 \mathrm{~Hz}$. From 10 to 20 profiles were collected in rapid succession over a 0.5 to $1.7 \mathrm{~h}$ time period and were grouped into 'sample ensembles'. Ensembles were initiated, on average, every $2.4 \mathrm{~h}$ except for a period of adverse winds and current directions. Turbulent kinetic energy dissipation rates $\left(\varepsilon\right.$, in units of $\left.\mathrm{W} \mathrm{kg}^{-1}\right)$ were derived from the velocity fluctuation profiles (Oakey \& Elliott 1982). The data were analyzed in $2 \mathrm{~s}$ segments blocked so that the last segment ended on the last data point where the instrument was still falling. Power spectra for the 2 shear profiles were computed, frequency-response corrections for the sensors and electronic transfer were applied, and variance due to spikes and noise was removed (Oakey 1982). All of the profiles in an ensemble were averaged together in 2 dbar depth bins using the maximum likelihood estimator for a lognormal distribution (Baker \& Gibson 1987). Data from the upper $8 \mathrm{~m}$ were not used because they were contaminated by turbulence created by the current flowing past the anchored research vessel.

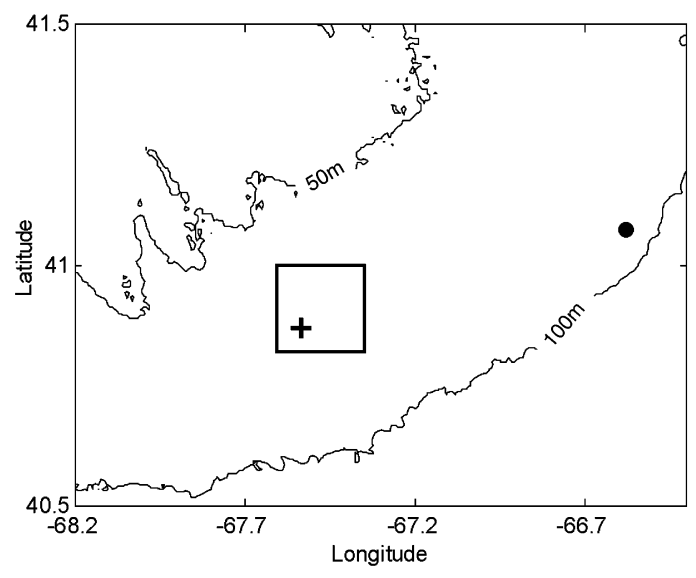

Fig. 1. Portion of the southern flank of Georges Bank showing location (+) where RV 'Seward Johnson' anchored for microstructure and zooplankton profiling on 11 to 15 June 1995. Open square measures $20 \times 20 \mathrm{~km}$ and encompasses the water area advected past the anchor station during the course of measurements (cf. Fig. 6); solid circle shows location of NOAA Buoy 44011 
Zooplankton in the upper $50 \mathrm{~m}$ of the water column were collected at discrete depths using a pumping system connected to a CTD. Collections were made during daylight hours between microstructure profiling sessions. Our strategy was to sample at $5 \mathrm{~m}$ intervals or less until we were at $40 \mathrm{~m}$, adding samples around major fluorescence features and density $\left(\sigma_{t}\right)$ gradients. Each zooplankton profile thus was constructed from individual collections made at 10 to 12 depths. The sampling system consisted of the following elements: (1) a PVC hose, $4 \mathrm{~cm}$ inside diameter and $60 \mathrm{~m}$ long, was attached to the CTD/rosette frame so that the opening was at the same depth as the CTD sensors; (2) a centrifugal pump submerged near the surface delivered $1 \mathrm{~m}^{3} \mathrm{~min}^{-1}$ from the sampling depth to a manifold on deck; and (3) a smaller hose, $1.9 \mathrm{~cm}$ inside diameter, was connected to the manifold and removed $301 \mathrm{~min}^{-1}$ from the main flow. We sampled the small flow for $1 \mathrm{~min}$, filtering the water through individual $40 \mu \mathrm{m}$-mesh samplers and preserving the retained zooplankton in $5 \%$ buffered formalin. When pumping, the CTD was stopped at desired depths long enough to clear the system entirely before we commenced sampling. The CTD record showed that the intake depth never varied by more than $\pm 1 \mathrm{~m}$ from the intended depth, and usually the range was $\pm 0.5 \mathrm{~m}$ or less.

In the laboratory, zooplankton samples were analyzed in 2 stages. First, we counted all copepodites and nauplii from each sample without further taxonomic identification. Abundance data (number $\mathrm{l}^{-1}$ ) were used to examine changes in vertical distribution and total abundance (upper $50 \mathrm{~m}$ ) over the $4 \mathrm{~d}$ of sampling. Then, for a subset of the profiles, we identified the species and developmental stages of the most abundant copepods to the lowest taxonomic level possible. The subset consisted of $3 \mathrm{~d}$ of sampling centered around a wind event where changes in the vertical distribution of copepods occurred. The enumerated taxa were Temora spp., Oithona spp., Pseudocalanus spp., and Calanus finmarchicus. To look at changes in the vertical distributions of each taxon over time, we standardized each profile so that the highest concentration for a given taxon in that profile had a value of ' 1 '. All other concentrations for that taxon in that profile were scaled to the highest concentration to give a relative concentration $(0.3,0.4$, etc.) at every other depth sampled in the profile. Vertical distributions were contoured for the set of profiles (that is, over time) by kriging the data. When kriging, we adjusted horizontal tension (anisotropy, up to a factor of 2) to make smooth connections between profiles. This was necessary because data density was much greater in the vertical dimension ( $5 \mathrm{~m}$ or less) than in the horizontal (sample spacing of $\sim 8 \mathrm{~h}$ during the day and $\sim 14 \mathrm{~h}$ between days).
We used the ship's $150 \mathrm{kHz}$ broad-band acoustic doppler current profiler (ADCP) to analyze water movements past the anchor site. Data were binned into $2 \mathrm{~m}$ depth intervals, averaged into 2 min ensembles, and corrected with bottom tracking data to provide estimates of absolute water velocity and direction. Horizontal velocities had a standard deviation of $0.8 \mathrm{~cm} \mathrm{~s}^{-1}$. Wind speed came from the ship's anemometer and from NOAA Buoy 44011, located $84 \mathrm{~km}$ to the east (Fig. 1). Wind speeds were corrected to a standard height of $10 \mathrm{~m}$ (Large \& Pond 1981).

\section{RESULTS}

We completed $10 \mathrm{CTD} /$ pump profiles over $4 \mathrm{~d}$ at the stratified site. With only a few exceptions, copepodites and copepod nauplii were most abundant in the upper $20 \mathrm{~m}$. Nauplii showed a tendency for shallower distributions than the copepodites. A subsurface chlorophyll maximum layer was present for the first half of the series near the base of the pycnocline (Fig. 2).

Except for Profile 106, most of the copepodites and the nauplii were above this feature. The depth of the pycnocline and the shape of the density profiles changed throughout the series, although surface and bottom $\sigma_{\mathrm{t}}$ values changed only slightly. There was no consistent relationship between the pycnocline and the depths of the copepod stages. In Profiles 106 and 115, copepodites assumed a deeper distribution than at other times. The nauplii at these 2 stations exhibited a variable vertical pattern, not as focussed as that for the copepodites but with some deepening compared with other nauplii profiles. Naupliar profiles at both these stations showed reduced abundances at $20 \mathrm{~m}$, with higher concentrations both above and below.

We examined the taxonomic composition of the most abundant copepods in the upper $25 \mathrm{~m}$ in Profiles 81 to 141. These data covered a $3 \mathrm{~d}$ period which included $1 \mathrm{~d}$ before and after the deepening of copepod stages in Profiles 106 and 115. The number of individuals of each species in samples collected below $25 \mathrm{~m}$ was always low, and for that reason we did not include them in this analysis. A broad range of copepodite and naupliar stages was found (Table 1).

Copepodite stages (Fig. 3A) of Temora spp. and Oithona spp. showed shallow distributions of 10 to $15 \mathrm{~m}$ on the first day, a deepening to $25 \mathrm{~m}$ on the second day, and a return to shallower depths on the third. Most Pseudocalanus spp. began the series at about $15 \mathrm{~m}$ and underwent some deepening and then shoaling on the second and third days, respectively. Another change in this genus occurred in the upper $15 \mathrm{~m}$, where the proportion of copepodites decreased markedly during the second day. Most of the Calanus fin- 


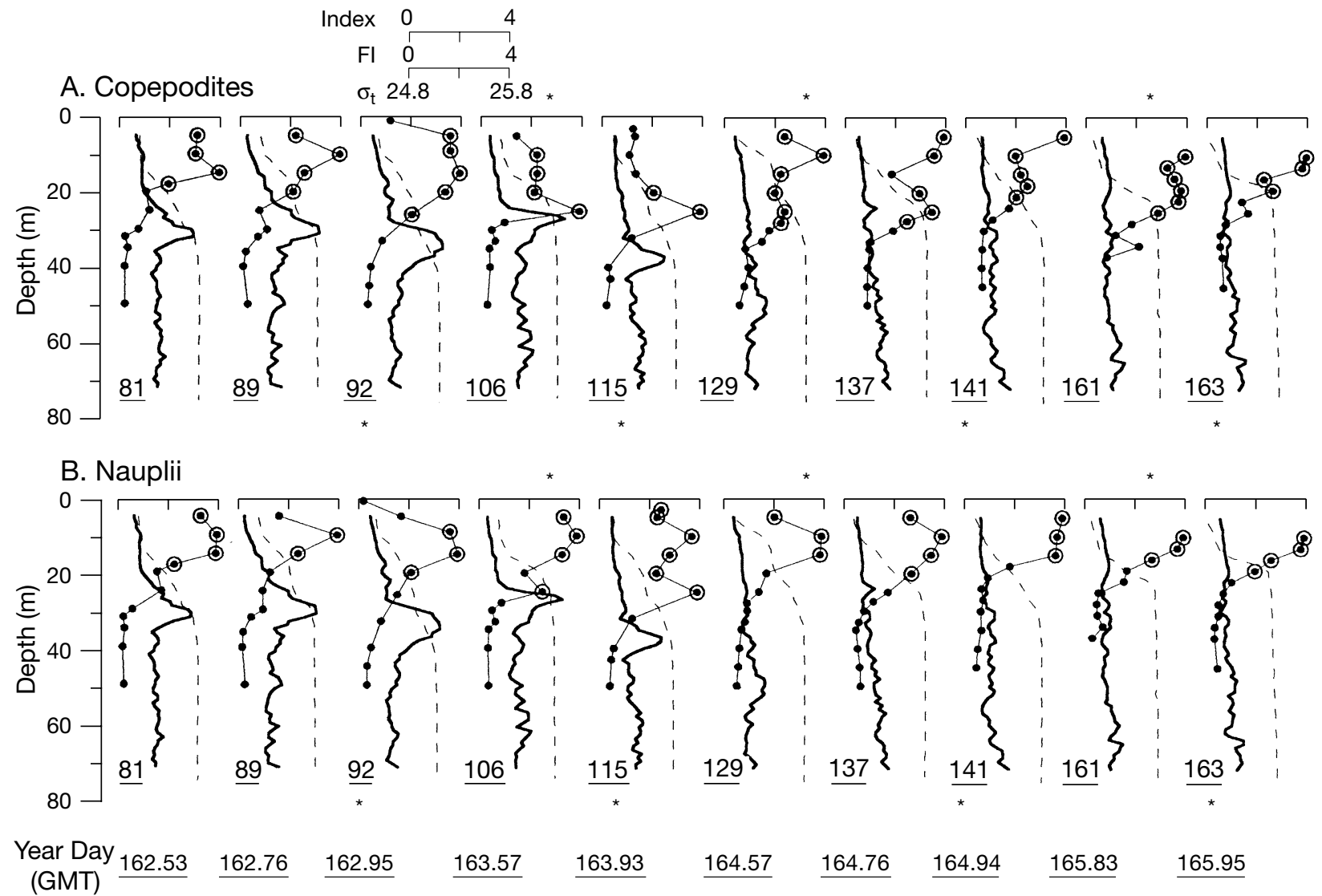

Fig. 2. (A) Vertical profiles of total copepodite stage abundance $(\bullet)$, fluorescence, FL (continuous line) and sigma- $t$ density (broken line) on 11 to 14 June; profile numbers are underlined; all profiles were taken during daylight between 10:00 and 18:45 $\mathrm{h}$; asterisks mark the last sample of each day, all taken between 18:00 and 18:45 $h_{\text {; }}$ copepodite abundances are index values $(0$ to 1.0) which are scaled to the highest abundance in each profile to emphasize the relative vertical patterns; open circles surround index values $\geq 0.5$ (i.e., where the concentration, no. $1^{-1}$, was $\geq 50 \%$ of the maximum concentration found in that profile); changes in abundance over time are shown in Fig. 8. (B) Vertical profiles of total naupliar stage abundance; further details as in (A). Time at the beginning of each profile is given at the bottom as year-day (GMT) for reference to other figures

Table 1. Mean stage composition (proportions) of copepodite (CI to CVI) and naupliar (NI to NVI) stages of dominant copepod taxa in Zooplankton Profiles 81 to 141

\begin{tabular}{|c|c|c|c|c|c|c|}
\hline Taxon & $\mathrm{CI}$ & CII & CIII & CIV & $\mathrm{CV}$ & CVI \\
\hline Temora spp. & 0.31 & 0.28 & 0.23 & 0.14 & 0.03 & 0.02 \\
\hline Oithona spp. & 0.02 & 0.05 & 0.07 & 0.13 & 0.29 & 0.44 \\
\hline Pseudocalanus spp. & 0.25 & 0.11 & 0.08 & 0.11 & 0.14 & 0.32 \\
\hline Calanus finmarchicus & 0.39 & 0.14 & 0.23 & 0.23 & 0.0 & 0.0 \\
\hline Taxon & NI & NII & NIII & NIV & NV & NVI \\
\hline Temora/Centropages spp. ${ }^{a}$ & 0.07 & 0.26 & 0.24 & 0.20 & 0.14 & 0.09 \\
\hline Oithona spp. & 0.23 & 0.15 & 0.26 & 0.18 & 0.10 & 0.08 \\
\hline Pseudocalanus/Metridia spp. & 0.26 & 0.17 & 0.26 & 0.26 & 0.04 & 0.01 \\
\hline Calanus finmarchicus & 0.23 & 0.14 & 0.31 & 0.16 & 0.15 & 0.02 \\
\hline \multicolumn{7}{|c|}{$\begin{array}{l}\text { a Nauplii of these taxa are difficult to distinguish. However, few Metridia } \\
\text { or Centropages spp. copepodites were found in the samples, so we as- } \\
\text { sume most nauplii belonged to the genera Pseudocalanus and Temora, } \\
\text { respectively }\end{array}$} \\
\hline
\end{tabular}

marchicus copepodites were deep (below $20 \mathrm{~m}$ ) to begin with, although some were found near the surface. None were found above $20 \mathrm{~m}$ on the second day.

Among the nauplii (Fig. 3B), the patterns varied between species. Temora spp. showed no discernible change over time. (Temora spp. were grouped with Centropages spp. because the early naupliar stages could not be distinguished between the 2 genera; however, adult Centropages were rare in these samples, and we therefore believe that most nauplii belonged to the abundant Temora.) Oithona spp. showed a deepening which appeared late in the second day, in Profile 115. Pseudocalanus spp. and Calanus finmarchicus had lower concentrations above $20 \mathrm{~m}$ in Profile 115 than they had at other times. (Pseudocalanus spp. are 

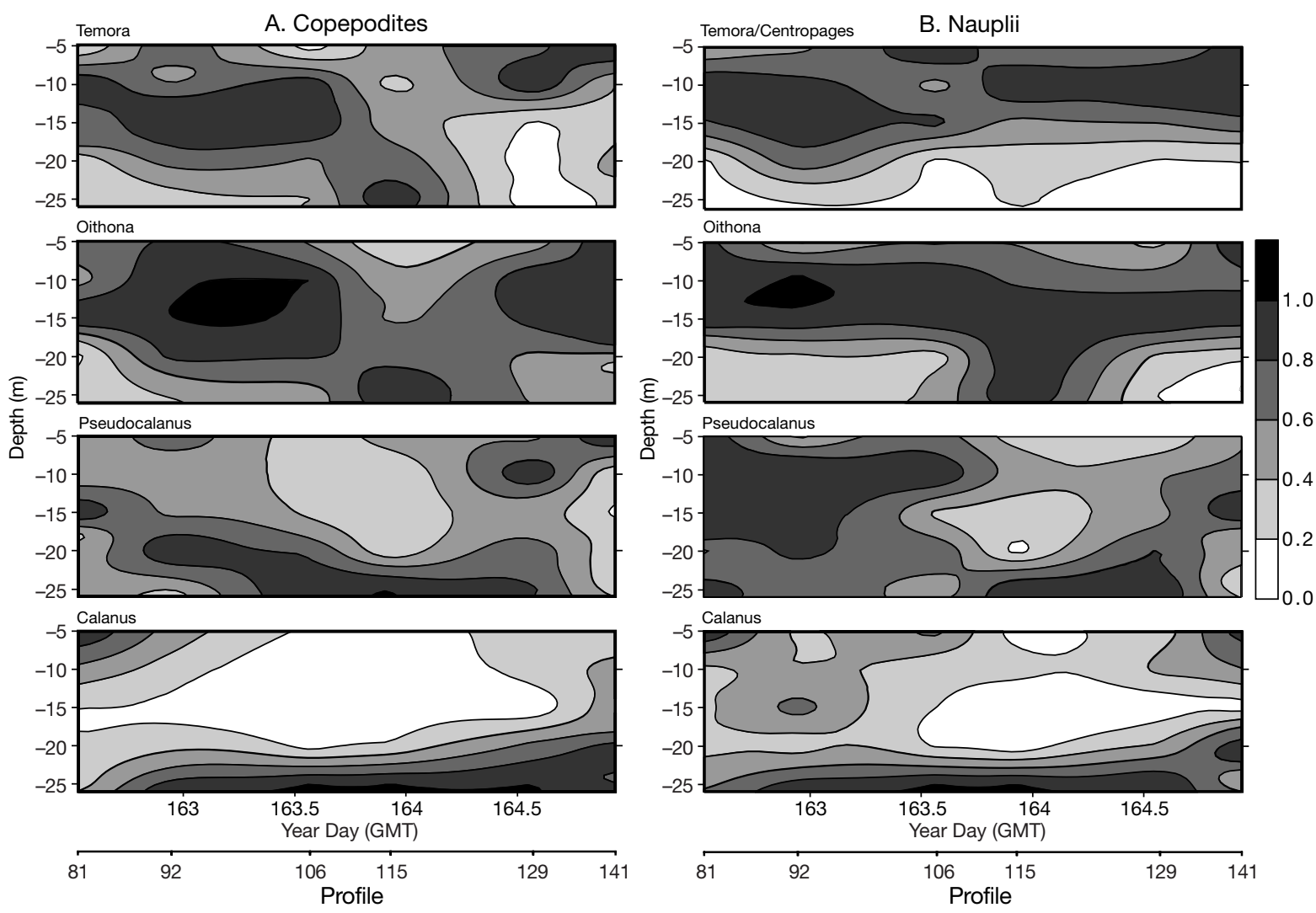

Fig. 3. Vertical distributions of (A) copepodites and (B) nauplii of abundant copepod taxa in the surface mixed layer during $3 \mathrm{~d}$ (11 to 13 June), with a wind event on the second day. Shaded contours show index values (0.2 gradations) during daylight hours, as in Fig. 2

grouped with Metridia spp. because the naupliar stages are difficult to distinguish, but adult female Metridia spp. were rare on the southern flank.) Table 2 summarizes the abundances of taxa used in Fig. 3; we simplified the table by using the names Temora and Pseudocalanus spp. without the other possible genera.

The ship's meteorological data acquisition system was not working from Year Day 164.5 to 165.5, a period of light wind following the principal wind event. We used wind data from NOAA Buoy 44011 to fill in during this period. Wind speed data from the ship were highly correlated with the buoy record when both systems were operating during this study ( $\mathrm{n}=84$ hourly comparisons, $\left.\mathrm{r}^{2}=0.75, \mathrm{p} \ll 0.001\right)$. Winds were $5 \mathrm{~m} \mathrm{~s}^{-1}$ or less for the first day of sampling (Profiles 81 to 92 in Fig. 2). They increased to $10 \mathrm{~m} \mathrm{~s}^{-1}$ before Profile 106 , and were steady through Profile 115 (data from the ship's record through this time period). By the following day (Profiles 129 and 137), winds were again light and remained $<8 \mathrm{~m} \mathrm{~s}^{-1}$ for the last $2 \mathrm{~d}$ of sampling (Fig. 4).

We completed 41 EPSONDE profiling ensembles in a little over 4 d. Fig. 4 shows dissipation rates $(\varepsilon)$ and sur- face wind stress during the $3 \mathrm{~d}$ period when we did the full taxonomic analysis. Epsilon values in the upper 10 to $20 \mathrm{~m}$ of the water column were $\leq 10^{-8} \mathrm{~W} \mathrm{~kg}^{-1}$ before

Table 2. Maximum concentrations and integrated abundances ( 5 to $25 \mathrm{~m}$ ) of copepod taxa in the pump profiles shown in Fig. 3. Data are means and (standard deviations) of all daytime profiles over $3 \mathrm{~d}$. Integrated abundance was calculated for each profile by trapezoidal summation of concentrations at each depth

\begin{tabular}{|lcc|}
\hline Stages & $\begin{array}{c}\text { Max. profile } \\
\text { concentration } \\
\left(\text { no. }^{-1}\right)\end{array}$ & $\begin{array}{c}\text { Integrated abundance } \\
\text { from 5 to } 25 \mathrm{~m} \\
\left(\text { no. }^{-2}\right) \times 1000\end{array}$ \\
\hline Copepodite & & \\
Temora spp. & $17.9(5.2)$ & $9.6(3.4)$ \\
Oithona spp. & $34.8(14.3)$ & $23.3(7.8)$ \\
Pseudocalanus spp. & $11.4(4.1)$ & $5.8(1.5)$ \\
Calanus finmarchicus & $21.0(13.9)$ & $7.8(3.5)$ \\
Naupliar & & \\
Temora spp. & $30.0(9.9)$ & $9.7(8.7)$ \\
Oithona spp. & $71.6(22.4)$ & $39.2(13.0)$ \\
Pseudocalanus spp. & $92.3(19.9)$ & $59.3(13.4)$ \\
Calanus finmarchicus & $27.5(12.2)$ & $12.7(6.3)$ \\
\hline
\end{tabular}



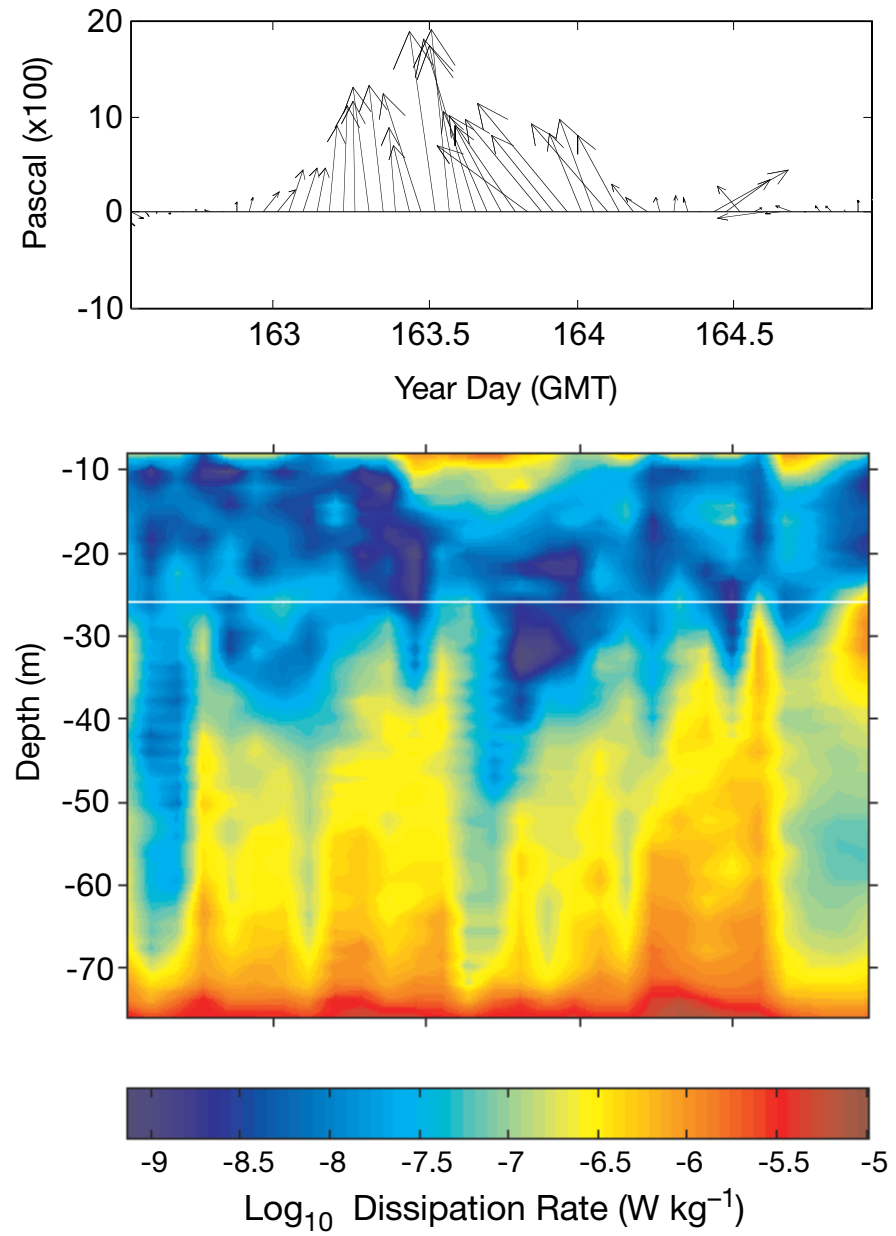

Fig. 4. Hourly average wind stress (upper graph; positive $\mathrm{Y}$ is North) and average turbulent energy dissipation rate, $\varepsilon$ (lower graph), on 11 to 13 June. The white line at $26 \mathrm{~m}$ on lower graph shows the lowest depth used in the detailed taxonomic analyses shown in Fig. 3. The frequency of EPSONDE (Oakey 1988) profiling is shown in the bottom axis of Fig. 5

Profiles 106 and 115. During Profiles 106 and 115, dissipation rates at 10 to $20 \mathrm{~m}$ ranged up to $10^{-6} \mathrm{~W} \mathrm{~kg}^{-1}$. After this, lower dissipation rates $\left(\varepsilon \leq 10^{-8} \mathrm{~W} \mathrm{~kg}^{-1}\right)$ returned to the upper 10 to $20 \mathrm{~m}$, although they were interspersed with some higher values. We used CTD data from the EPSONDE to plot changes in density structure over time (Fig. 5). The pycnocline was nearest the surface on the first day of sampling and deepened on the second day. The deepening (ca Year Day 163.25 to 163.75 ) coincided with the onset and strengthening of winds shown in Fig. 4. Temperatures were around 8.5 to $10.5^{\circ} \mathrm{C}$ in the upper mixed layer, 7 to $8^{\circ} \mathrm{C}$ in the pycnocline, and 6 to $6.5^{\circ} \mathrm{C}$ in the bottom layer.

The current record at $15 \mathrm{~m}$ depth taken from the ship's ADCP shows that on- and off-bank excursions of the semi-diurnal tide were approximately $8 \mathrm{~km}$ at the anchor site, and that the along-isobath residual velocity averaged $3.8 \mathrm{~km} \mathrm{~d}^{-1}$ to the southwest. While all sampling took place at the anchor site, it is possible to invert the ADCP record to back-calculate the approximate initial geographical positions of the parcels sampled at $15 \mathrm{~m}$ depth (Fig. 6A). This calculation shows that the samples came from within an area of about $10 \times 20 \mathrm{~km}$. The largest along-isobath distance between average daily positions of the zooplankton pump samples was the $\sim 5 \mathrm{~km}$ that separated Day 1 from Day 2. The spatial distribution of the subsurface chlorophyll maximum in the study area at the beginning of our profiling session is indicated in similar fashion by a back-calculation of the maximum fluorescence values from all CTD casts (Fig. 6B). Analysis of ADCP data showed that horizontal shear over the depth range from $15 \mathrm{~m}$ to the chlorophyll maximum was small.

The distinct subsurface chlorophyll maximum layer that was present when we began sampling disappeared after Cast 115 (see profiles in Fig. 2). Was this a temporal phenomenon or a spatial one? Fig. 6B shows that there was a strong horizontal spatial gradient in the chlorophyll when we began our work. The high fluorescence region along the southern margin of the sampled area moved to the anchor site only during the on-bank portion of the tidal cycle. Pump profiles occurred at various parts of the tidal cycle, sampling relatively high chlorophyll concentrations through Cast 106, and thereafter missing them (Fig. 7). The integrated abundance of copepodites in each pump profile shows a slight decline after Cast 115 that persisted (Fig. 8). The shift after cast 115 coincided with samples occurring outside the region of high chlorophyll fluorescence (Fig. 6). Most of the decline in copepodite abundance was due to a decline in Oithona spp. A small shift in naupliar abundance also occurred.

During April and May 1995, winds $\geq 10 \mathrm{~m} \mathrm{~s}^{-1}$ were recorded $14 \%$ of the time at Buoy 44011. Most of these occurred as isolated events, similar to the event we sampled during this cruise.

\section{DISCUSSION}

It is often difficult to distinguish changes due to vertical processes from those resulting from horizontal variability and advection. Since we sampled at a fixed site, the ADCP record was essential for reconstructing the flow field and helping to discriminate between the temporal and spatial characteristics of our data. In this study, the principal variables were the vertical distribution and abundance of copepods, profiles of $\sigma_{\mathrm{t}}$, fluorescence and turbulent kinetic energy dissipation rate, and wind. In this discussion we focus on processes in 
the surface mixed layer and the pycnocline. The pattern of increasing and decreasing dissipation rates below the pycnocline was generated by tidal shear along the bottom, which we do not address further. For convenience, we use the word 'turbulence' instead of the term 'dissipation rate' which was actually calculated. We use the latter only when supplying values to describe different levels of turbulence.

Our data show that most copepod stages on the stratified southern flank of Georges Bank in early June inhabited shallower depths, $\sim 10$ to $15 \mathrm{~m}$, when the surface was quiescent $\left(\varepsilon \sim 10^{-8}\right.$ to $10^{-9} \mathrm{~W} \mathrm{~kg}^{-1}$ ) than when it was turbulent. When dissipation rates at $10 \mathrm{~m}$ increased up to $10^{-6.5} \mathrm{~W} \mathrm{~kg}^{-1}$, most of the copepodites and many of the nauplii were found at around 20 to $25 \mathrm{~m}$. There, dissipation rates were similar to the values in which the copepods had been residing previously. Few copepods were located below this level although the zone of low turbulence in our particular example extended deeper (cf. Figs. $2 \& 4$ ). The

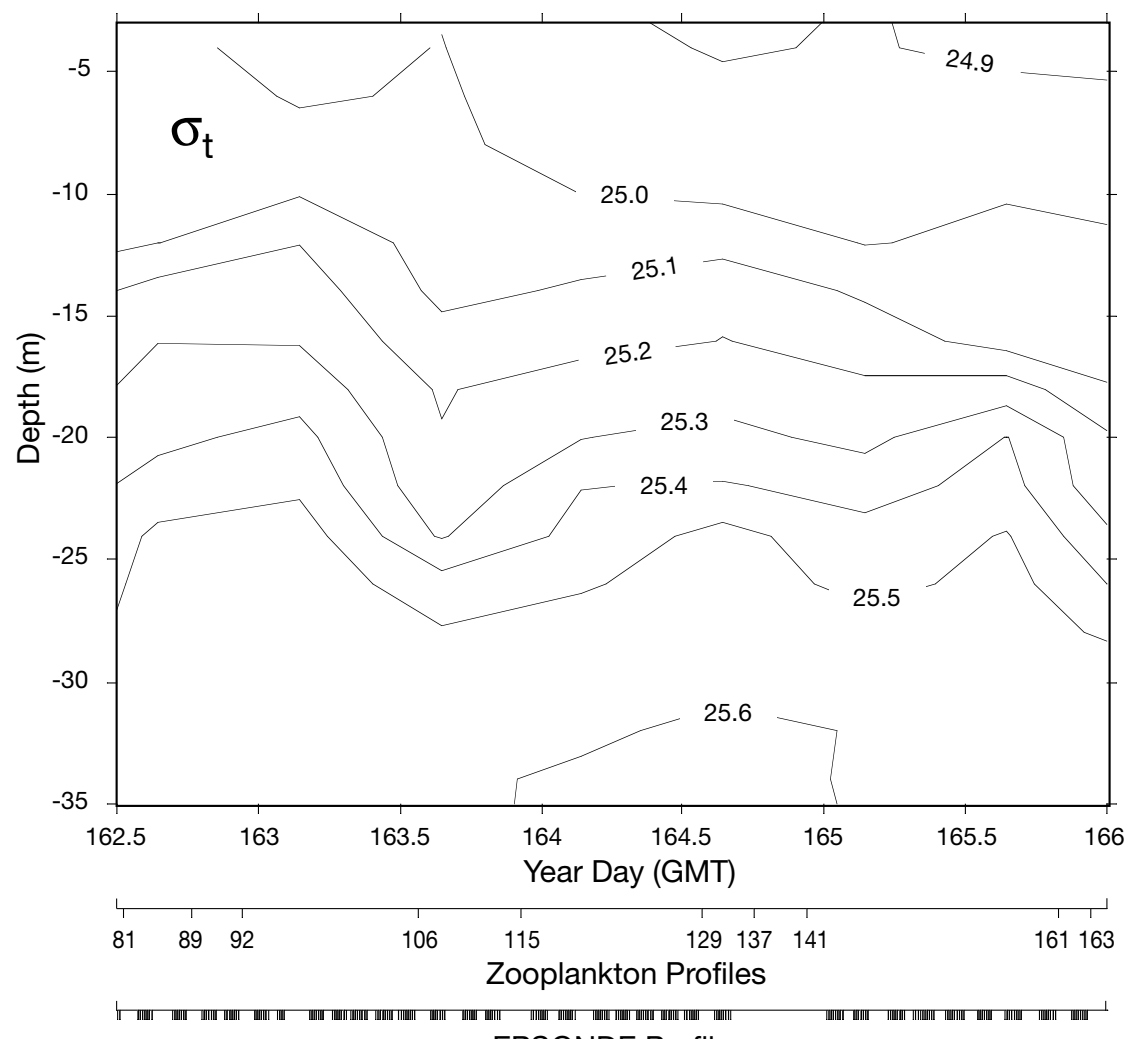

EPSONDE Profiles

Fig. 5. Density $\left(\sigma_{\mathrm{t}}\right)$ structure in the upper $35 \mathrm{~m}$, obtained from EPSONDE casts (614 profiles, shown on bottom axis). Year Day (GMT) and pump profile numbers are given for reference to other figures
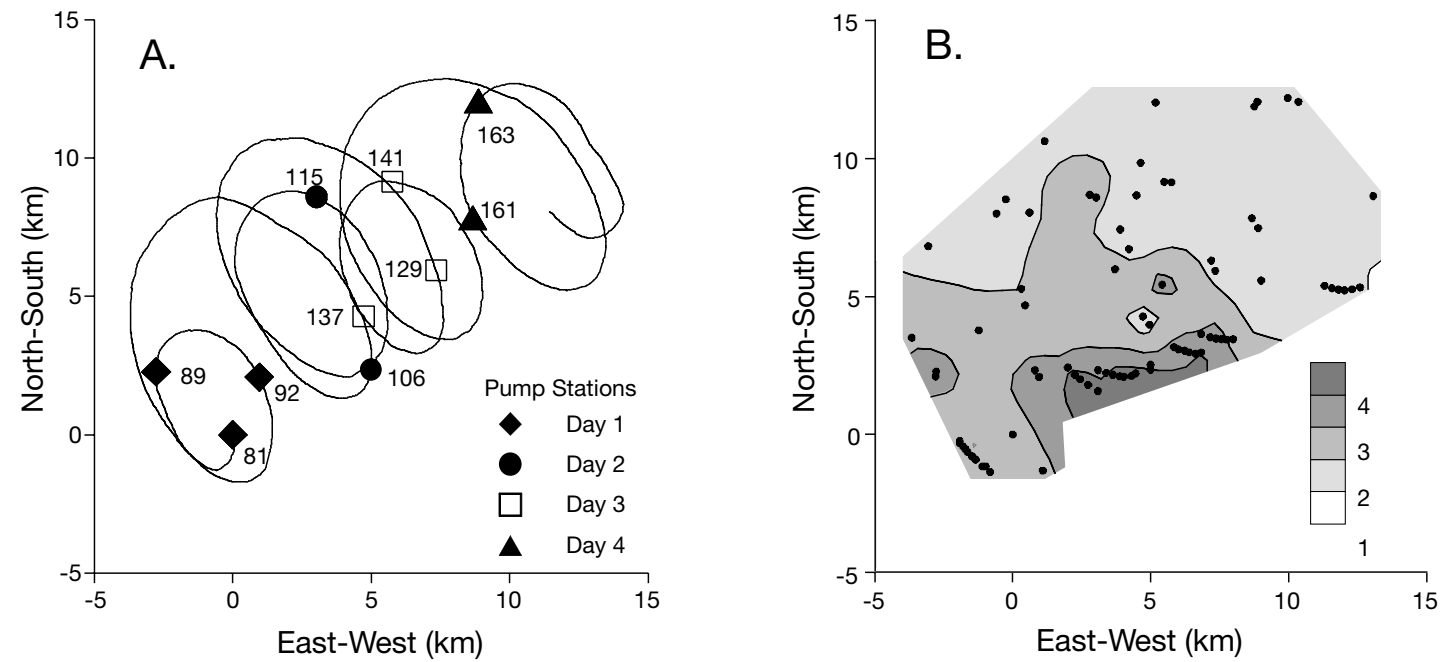

Fig. 6. (A) Theoretical trajectory (continuous line) of a water parcel at $15 \mathrm{~m}$ depth on 11 to 14 June, back-calculated from the anchor station (\#81) using records from the ship-mounted $150 \mathrm{kHz}$ broad-band Acoustic Doppler Current Profiler (ADCP); all displacements are shown relative to the first zooplankton profile at the origin $(0,0)$, making this a re-creation of synoptic positions at the beginning of the observation period; numbers next to the symbols refer to zooplankton profiles; symbols distinguish between sampling days; axes are $20 \mathrm{~km}$ long and correspond to the square area in Fig. 1. (B) Maximum water-column fluorescence values (shaded values, in volts) from all CTD casts beginning with Cast 81; the back-calculated positions of the casts $(\bullet)$ were derived from the ADCP record as above; the anchor station can be identified at the origin; the areal distribution of fluorescence is a synoptic recreation and can be translated directly to (A); the vertical distribution of fluorescence at selected stations can be seen in the profiles in Fig. 2 


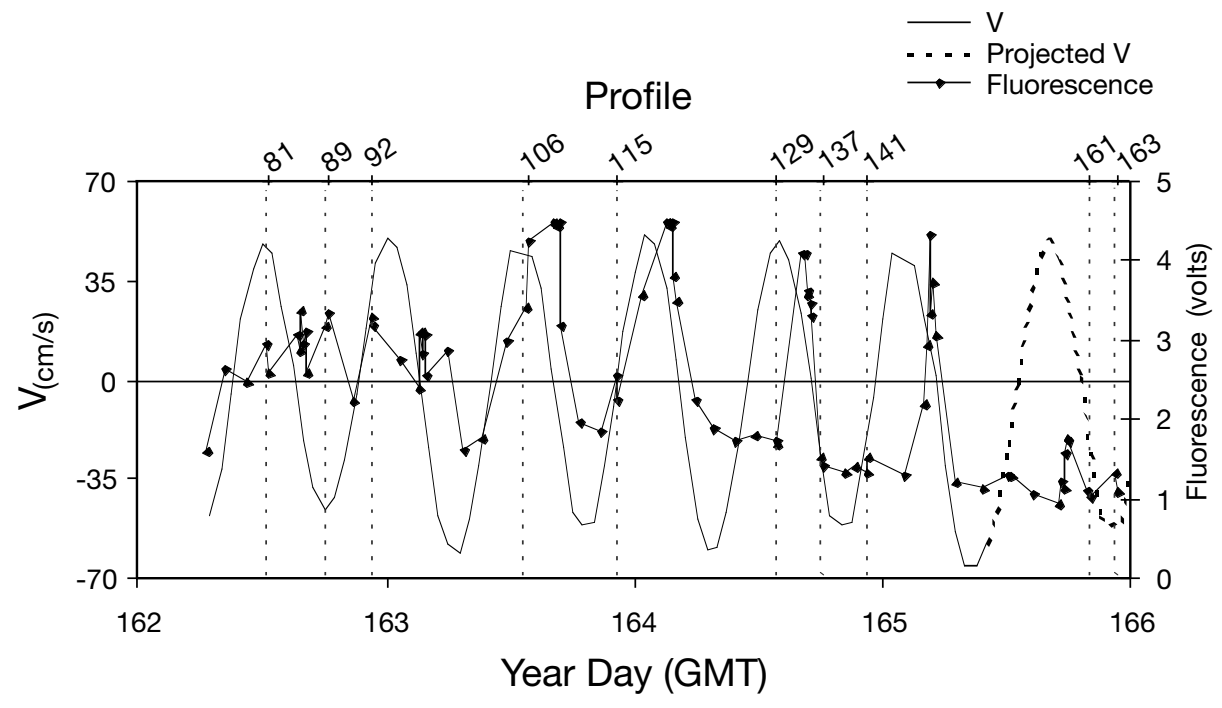

Fig. 7. Relationship between maximum water-column fluorescence, tidal velocity, and the timing of zooplankton pump profiles at the anchor station on 11 to 14 June. Fluorescence data are from CTD casts in Fig. 6B. Velocity measurements are hourly averages for the water column from the $150 \mathrm{kHz}$ broad-band ADCP. The ADCP was not working after Year Day 165.5, so values were projected from the prior record following the diurnal asymmetry in the tides. All zooplankton profiles are indicated along the upper border. ' $\mathrm{V}$ ' is positive during northward (on-shelf) flow, which occurs during the flooding tide. Large fluorescence values were recorded during the second and third day of plankton profiling near the maximum on-shelf extent of the tide (where $\mathrm{V}$ approaches zero from positive values). Zooplankton were sampled in water with declining fluorescence values after Cast 106, even though the chlorophyll feature remained in the area for 3 more tidal cycles (compare this time series with positions of high fluorescence and zooplankton profiles in Fig. 6)

change from shallow to deeper depths involved a change from the bottom of the surface mixed layer to near the bottom of the pycnocline. Were the changes in vertical distribution due to increased turbulence at the surface, or were they due to other factors such as advection, changes in pycnocline depth, or changes in the sampling efficiency of the pump? Our analysis suggests that changes in the vertical distribution of cope-

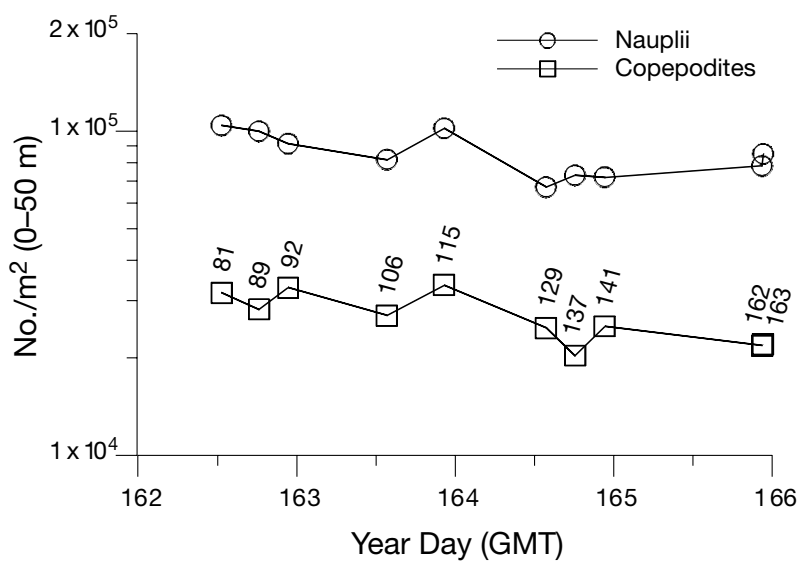

Fig. 8. Integrated abundance of copepodites and copepod nauplii in the upper $50 \mathrm{~m}$ (shallowest to deepest sample from each profile) at the anchor station on 11 to 14 June. Abundance was calculated using trapezoidal summation pods resulted primarily from vertical, time-varying processes; the strongest association was with turbulence.

Profiles of fluorescence changed over the course of our measurements, but not in a manner that explains the changes in copepod distributions. The subsurface fluorescence maximum was present in zooplankton profiles taken before and during the wind event (Fig. 2). This maximum did not disappear as a result of wind mixing, as one might suppose from the time series of profiles in Fig. 2. Mixing from the surface appears to have eroded into the top of the pycnocline (Fig. 5), but it did not extend the 25 to $30 \mathrm{~m}$ required to disrupt the chlorophyll maximum (cf. distribution of dissipation rates in Fig. 4 with fluorescence profiles in Fig. 2). Rather, our zooplankton profiles subsequent to No. 115 were taken outside the area of high subsurface chlorophyll because of the timing of pump samples relative to movement of the feature by the tides (onand off-bank) and the residual, southwestward flow (Figs. 6 \& 7).

With respect to the spatial pattern of chlorophyll, it is not possible to completely and unequivocally separate temporal from spatial changes because of the manner in which we reconstructed the distribution. Yet, our approach revealed ample spatial structure in the chlorophyll distributions early in our profiling and before the wind event (Fig. 6). The along- and across- 
shelf patterns of advection throughout our study were very regular and not suspect, and the feature was mapped independently by Sieracki et al. (1998) using rapid survey techniques from another vessel while we were anchored at our study site. Accordingly, we interpret the change in chlorophyll after Cast 115 to be due primarily to advection and not temporal changes in the feature.

The decline in integrated abundance of copepods after Cast 115 (Fig. 8) appears to have been part of a spatial shift in abundance (mostly Oithona spp.) that coincided with the edge of the chlorophyll patch. With the shift in copepod abundance, however, there was no systematic change in stage composition that might account for changes in vertical distributions of any of the taxa. During the wind event, neither the integrated abundance of copepods in the upper $25 \mathrm{~m}$ (Fig. 8), nor the abundance of Temora spp. nauplii in the surface layer (Fig. 3) changed, so we have no reason to suspect changes in sampling efficiency of the pump system under turbulent conditions. Finally, Profiles 106 and 115 (the 'wind-event' profiles) were sampled at opposite ends of the tidal cycle and were in close proximity to the post-event stations where we sampled the return of copepods to their previously shallow depths (Fig. 6A). This would require a very tightly constrained spatial pattern of change, if that were all that had happened. Thus, we conclude that changes in vertical distributions of copepods were temporal, not spatial, changes; and that there was downward movement of most copepods during the wind event and a rapid return to shallower depths afterward. These movements did not simply follow changes in isopycnoclinal layers. The pycnocline deepened before we saw a corresponding change in copepods, and the copepods changed again, shoaling after the wind event, when the pycnocline did not (Figs. 3 \& 5). What is indicated, therefore, is active movement of the various copepod stages across an environmental gradient of depth, temperature and density. We cannot rule out the possibility that the initial downward movement was made to follow the environmental conditions near the top of the pycnocline, since increased turbulence and deepening of the pycnocline occurred together. We note, however, that regions of relatively low turbulence remained a common factor in the depth of the copepod maxima throughout the sampling period. Our data suggest that the downward response was faster for the copepodite stages of Temora spp., Pseudocalanus spp. and Calanus finmarchicus than Oithona spp., and more complete for the copepodites than for any of the nauplii. These differences between taxa and stages support the idea that the changes were due to behavior, but greater temporal resolution would be needed to confirm this.
Since we were able to sample only 1 cycle of change, more observations will be needed to determine if the movements were due to changes in turbulence alone or to other factors, and to determine whether such movements can be expected generally during mixing events or are complicated by too many other factors to be predicted readily. In the meantime, findings from other areas substantiate our inference that turbulence was an important determinant of vertical position in our study. Mackas et al. (1993) suggested that 2 groups of large calanoid copepods from the central North Pacific were separated vertically by preferences or tolerances for different levels of turbulence which were measured during the cruise, and that the vertical zonation between them was influenced by the depth of mixing from the surface. Neocalanus cristatus and Eucalanus bungii apparently preferred depths with lower turbulence and adjusted their vertical position accordingly. $N$. plumchrus and $N$. flemingerii occupied shallower positions with more variable levels of turbulence. Working from a research submarine in the California Current system, Haury et al. (1990) measured changes in $\varepsilon$ and abundance of different zooplanktonic taxa at a fixed depth of $17 \mathrm{~m}$. They suggested that increased turbulence resulted in mixing of weaker swimming taxa near the surface (larvaceans were mixed downward, Oithona spp. upward), and avoidance of elevated turbulence by stronger vertical migrators (Metridia pacifica). Limitations of sampling methods precluded an assessment of changes at other depths (see comments in Haury et al. 1992). Lagadeuc et al. (1997) sampled from an anchor station in the Baie des Chaleurs, Canada, for $52 \mathrm{~h}$. They estimated smallscale turbulence from wind stress calculations and used hydrographic properties and Richardson number calculations (Mann \& Lazier 1991) to document deepening of the surface mixed layer (from about $5 \mathrm{~m}$ to $10 \mathrm{~m}$ ). Wind speeds in their wind event averaged $9.2 \mathrm{~m}$ $\mathrm{s}^{-1}$, similar to ours. The authors showed that copepodites of Temora longicornis and Pseudocalanus spp. assumed deeper distributions in more stable layers (areas of higher Richardson number) during the wind event. This behavior agrees with our findings. In their study, naupliar stages (mostly $T$. longicornis) became less stratified (their original peak concentration was at 6 to $8 \mathrm{~m}$ ) and were more evenly distributed in the upper $10 \mathrm{~m}$ during the mixing event. Their data do not agree with ours on this point, but they looked more closely at the near-surface layer than we did (every $2 \mathrm{~m}$ in their study vs our 3 samples in the upper $10 \mathrm{~m}$ ). Our results do agree in that Temora spp. nauplii did not submerge to deeper, more stable layers when surface mixing increased. Temora spp. are abundant in the shoal regions of Georges Bank (Davis 1987), where turbulence is greater (Horne et al. 1996), and it is pos- 
sible that this species is particularly well adapted to higher levels of turbulence. Still, in both Lagadeuc et al.'s study and ours, the copepodites of this genus were deeper when a stable/less turbulent region was available.

If turbulence dominated the brief (approximately day-long) changes that we saw on Georges Bank, then several questions follow. How would these organisms respond to mixing events of longer duration: would they acclimate and return to shallow depths, or remain below the layer of elevated turbulence? What about a wind event of greater intensity: would copepods have 'escaped' from the surface or been mixed through the upper layer? Several studies have shown mixing of zooplankton in the surface mixed layer (Mullin et al. 1985, Dagg 1988, Incze et al. 1990), but our results suggest additional possibilities, at least under moderate conditions. To what extent does turbulence explain patterns of vertical distribution that otherwise might be attributed to other factors? For example, if a zooplankton maximum is associated with a subsurface chlorophyll maximum (SSCM), it might be interpreted as a positive response of zooplankton to the elevated chlorophyll concentrations. In our study, several taxa were near the SSCM during the mixing event, but otherwise were not near this layer even when the SSCM was well developed (Profiles 81 to 92 in Fig. 2). Other taxa (Pseudocalanus spp. and Calanus finmarchicus) were most abundant at depth whether or not the SSCM was there. Finally, we should examine the effects of surface turbulence on vertical migrators (e.g., Haury et al. 1990) and on other taxonomic groups.

Is a vertical difference of 10 to $15 \mathrm{~m}$, as we detected, important? The event reported here, with a wind speed of $10 \mathrm{~m} \mathrm{~s}^{-1}$ for $<10 \mathrm{~h}$, was a mild one, which can occur frequently on Georges Bank and in other coastal waters during spring. Even if the reaction of the copepods is short-lived, it may have consequences for trophic interactions and for modeling of such interactions. Of current interest is the effect of shear velocity on feeding in the plankton. Theory and evidence from field and laboratory studies indicate that, for some organisms, increased turbulence (up to a critical threshold) may have a positive effect on particle encounter rates and feeding (Rothschild \& Osborn 1988, MacKenzie \& Kiørboe 1995, 2000, Saiz \& Kiørboe 1995, Dower et al. 1997). The work conducted to date assumes a system in which predators and prey accept the imposed changes in turbulence; neither theory nor experiments account for the fact that zooplankton and ichthyoplankton might adjust their depth in response to these changes. In our study, the apparent downward movement of most copepods resulted in lower concentrations in the zone of high turbulence and increased concentrations at depths of lower turbulence (Laga- deuc et al. 1997 achieved similar results). The former reduces the putative positive effect of turbulence on encounter rates; the latter might result in increased feeding at depth (for instance, larval fish preying on enhanced concentrations of copepods), but not for the reasons currently accounted for by turbulence theory. Consequently, one cannot simply apply the increased turbulent velocities to encounter-rate formulations (Rothschild \& Osborn 1988). One must consider the specific reactions of prey (whether or not they migrate in response to changing turbulence or associated conditions) and predators (such as their preferred depths, the light conditions under which they feed most effectively, and their own responses to turbulence and shifts in prey distributions: Heath et al. 1988, MacKenzie \& Kiørboe 1995, 2000, Dower et al. 1997). The varied reactions of different species and stages of copepods in our study help to explain the complicated depth distributions seen for the aggregated data in Fig. 2, and may help explain variable depth distributions in other situations as well.

Turbulence threshholds for the vertical behavior of copepods in the field are not well known, although much is being learned about performance capabilities from laboratory experiments (Marrase et al. 1990, Saiz et al. 1992, Alcarez et al. 1994, Saiz 1994, Saiz \& Kiørboe 1995). These studies indicate that feeding by Acartia tonsa, for example, is enhanced up to turbulence levels of about $10^{-6} \mathrm{~W} \mathrm{~kg}^{-1}$, after which it may decline (Saiz \& Kiørboe 1995). The threshold between increasing and decreasing feeding rates occurs at a relatively high level of turbulence, consistent with a general expectation that planktonic organisms are adapted to the conditions they commonly experience there. The apparent submergence of copepodites and nauplii in our study occurred at turbulence levels of about $10^{-6.5} \mathrm{~W} \mathrm{~kg}^{-1}$, which 'fits' reasonably well with the performance data generated for Acartia tonsa above. It is noteworthy, however, that when lower levels of turbulence were available, most of the taxa in our study were found there. Without a refuge of low turbulence, we might not have seen such movements. The selection of vertical position in the water column undoubtedly is influenced by many factors, including food availability and individual feeding modes (Tiselius \& Jonsson 1990, Mackas et al. 1993, Saiz \& Kiørboe 1995), which deserve closer scrutiny under varied conditions.

Acknowledgements. This research was conducted as part of the US GLOBEC Northwest Atlantic/Georges Bank Program, sponsored by the National Science Foundation and the National Oceanic and Atmospheric Administration. This work was supported by the following NSF grants: OCE-9313669 and OCE-9634165 to L.S.I.; OCE-9631175 to D.H. and N.O.; and 
OCE-9313671 to Robert Beardsley, Woods Hole Oceanographic Institution. We gratefully acknowledge the assistance provided by officers and crew of RV 'Seward Johnson' and the Marine Technical Group from the University of Miami. We add special thanks to Bob Ryan, Liam Petrie and Ed Verge who provided EPSONDE technical support, Dave Senciall for providing us the loadtran program for ADCP processing, and Russ Burgett for processing the physical data. Drs Tom Miller, Thomas Kiørboe and an anonymous reviewer provided helpful comments and discussions. This is GLOBEC Contribution No. 177.

\section{LITERATURE CITED}

Baker MA, Gibson CH (1987) Sampling turbulence in the stratified ocean: statistical consequences of strong intermittency. J Phys Oceanogr 17:1817-1836

Bollens SM, Stearns DE (1992) Predator-induced changes in the diel feeding cycle of a planktonic copepod. J Exp Mar Biol Ecol 156:179-186

Brown BE (1987) The fisheries resources. In: Backus RH (ed) Georges Bank. MIT Press, Cambridge, p 480-493

Buckley LJ, Lough RG (1987) Recent growth, biochemical composition, and prey field of larval haddock (Melanogrammus aeglefinus) and Atlantic cod (Gadus morhua) on Georges Bank. Can J Fish Aquat Sci 44:14-25

Butman B, Loder JW, Beardsley RC (1987) The seasonal mean circulation: observation and theory. In: Backus RH (ed) Georges Bank. MIT Press, Cambridge, p 125-138

Checkley DM, Uye S, Dagg MJ, Mullin MM, Omori M, Onbe T, Zhu MY (1992) Diel variations of the zooplankton and its environment at neritic stations in the inland sea of Japan and the northwest Gulf of Mexico. J Plankton Res 14:1-40

Costello JH, Strickler JR, Marasse C, Trager G, Zeller R, Freise AJ (1990) Grazing in a turbulent environment: behavioral response of a calanoid copepod, Centropages hamatus. Proc Natl Acad Sci USA 87:1648-1652

Dagg MJ (1988) Physical and biological responses to the passage of a winter storm in the coastal and inner shelf waters of the northern Gulf of Mexico. Cont Shelf Res 8:167-178

Davis CS (1987) Zooplankton life cycles. In: Backus RH (ed) Georges Bank. MIT Press, Cambridge, p 256-267

Denman KL, Gargett AE (1988) Multiple thermoclines as barriers to vertical exchange in the subarctic Pacific during SUPER, May 1984. J Mar Res 46:77-103

Dower JF, Miller TJ, Leggett WC (1997) The role of microscale turbulence in the feeding ecology of larval fish. Adv Mar Biol 31:169-220

Flagg CN (1987) Hydrographic structure and variability. In: Backus RH (ed) Georges Bank. MIT Press, Cambridge, p 108-124

Frost BW, Bollens SM (1992) Variability of diel vertical migration in the marine planktonic copepod Pseudocalanus newmani in relation to its predators. Can J Fish Aquat Sci 49:1137-1141

Gargett AE (1989) Ocean turbulence. Annu Rev Fluid Mech 21:419-451

Gargett AE (1997) 'Theories' and techniques for observing turbulence in the ocean euphotic zone. Sci Mar 61(Suppl. 1):25-45

Haury LR, Yamazaki H, Itsweire EC (1990) Effects of turbulent shear flow on zooplankton. Deep-Sea Res 37:447-461

Haury LR, Yamazaki H, Frey CL (1992) Simultaneous measurements of small-scale physical dynamics and zooplankton distributions. J Plankton Res 14:513-530
Hays GC, Warner AJ, Tranter P (1997) Why do the two most abundant copepods in the North Atlantic differ so markedly in their diel vertical migration behaviour? J Sea Res 38:85-92

Heath MR, Henderson EW, Baird DL (1988) Vertical distribution of herring larvae in relation to physical mixing and illumination. Mar Ecol Prog Ser 47:211-228

Horne EPW, Loder JW, Naimie CE, Oakey NS (1996) Turbulence dissipation rates and nitrate supply in the upper water column on Georges Bank. Deep-Sea Res II 43: 1683-1712

Incze LS, Ortner PB, Schumacher JD (1990) Microzooplankton, vertical mixing and advection in a larval fish patch. J Plankton Res 12:365-379

Kiørboe T, Saiz E (1995) Planktivorous feeding in calm and turbulent environments, with emphasis on copepods. Mar Ecol Prog Ser 122:135-145

Lagadeuc Y, Boule M, Dodson JJ (1997) Effect of vertical mixing on the vertical distribution of copepods in coastal waters. J Plankton Res 19:1183-1204

Large WG, Pond S (1981) Open ocean momentum flux measurements in moderate strong winds. J Phys Oceanogr 11: 324-336

Limeburner R, Beardsley RC (1996) Near surface recirculation over Georges Bank. Deep-Sea Res II 43:1547-1574

Mackas DL, Sefton H, Miller CB, Raich A (1993) Vertical habitat partitioning by large calanoid copepods in the oceanic subarctic Pacific during Spring. Prog Oceanogr 32:259-294

MacKenzie BR, Kiørboe T (1995) Encounter rates and swimming behavior of pause-travel and cruise larval fish predators in calm and turbulent laboratory environments. Limnol Oceanogr 40:1278-1289

MacKenzie, BR, Kiørboe T (2000) Larval fish feeding and turbulence: a case for the downside. Limnol Oceanogr 45: $1-10$

MacKenzie BR, Leggett WC (1991) Quantifying the contribution of small-scale turbulence to the encounter rates between larval fish and their zooplankton prey: effects of wind and tide. Mar Ecol Prog Ser 73:149-160

Mann KH, Lazier JRN (1991) Dynamics of marine ecosystems. Blackwell, Oxford

Marrase C, Costello JHT, Granata Y, Strickler JR (1990) Grazing in a turbulent environment: energy dissipation, encounter rates and the efficacy of feeding currents in Centropages hamatus. Proc Natl Acad Sci USA 87:1653-1657

Mullin MM, Brooks ER, Reid FMH (1985) Vertical structure of nearshore plankton off southern California: a storm and larval fish food web. Fish Bull Calif 83:151-170

Neill WE (1990) Induced vertical migration in copepods as a defense against invertebrate predation. Nature 345:524-526

Neill WE (1992) Population variation in the ontogeny of predator-induced vertical migration of copepods. Science 356:54-57

Oakey NS (1982) Determination of the rate of dissipation of turbulent energy from simultaneous temperature and velocity shear microstructure measurements. J Phys Oceanogr 12:256-271

Oakey NS (1988) Statistics of mixing parameters in the upper ocean during JASIN Phase 2. J Phys Oceanogr 15: 1662-1675

Oakey NS, Elliott JA (1982) Dissipation within the surface mixed layer. J Phys Oceanogr 12:171-185

Ohman MD (1990) The demographic benefits of diel vertical migration by zooplankton. Ecol Monogr 60:257-281

Osborn TR (1996) The role of turbulent diffusion for copepods with feeding currents. J Plankton Res 18:185-195 
Rothschild BJ, Osborn TR (1988) Small-scale turbulence and plankton contact rates. J Plankton Res 10:465-474

Saiz E (1994) Observations of the free-swimming behavior of Acartia tonsa: effects of food concentration and turbulent water motion. Limnol Oceanogr 39:1566-1578

Saiz E, Alcaraz M (1992) Free-swimming behaviour of Acartia clausi (Copepoda: Calanoida) under turbulent water movement. Mar Ecol Prog Ser 80:229-236

Saiz E, Kiørboe T (1995) Predatory and suspension feeding of the copeppod Acartia tonsa in turbulent environments. Mar Ecol Prog Ser 122:147-158

Saiz E, Alacaraz M, Paffenhöffer GA (1992) Effects of smallscale turbulence on feeding rate and gross growth efficiency of three Acartia species. J Plankton Res 14: 1085-1097

Sieracki ME, Gifford DJ, Gallager SM, Davis CS (1998) Ecology of a Chaetoceros socialis Lauder patch on Georges Bank: distribution, microbial associations and grazing losses. Oceanography 11:30-35

Editorial responsibility: Thomas Kiørboe (Contributing Editor), Charlottenlund, Denmark
Simpson JH, Crawford WR, Rippeth TP, Campbell AR, Cheok JVS (1996) The vertical structure of turbulent dissipation in shelf seas. J Phys Oceanogr 26:1579-1590

Tiselius P, Jonsson PR (1990) Foraging behavior of six calanoid copepods: observations and hydrodynamic analysis. Mar Ecol Prog Ser 66:23-33

Wiebe PH, Beardsley RC, Bucklin A, Mountain DG (2001) Introduction to coupled biological and physical studies of plankton populations in the Georges Bank region and related North Atlantic GLOBEC study sites. Deep-Sea Res II (in press)

Yamazaki H, Osborn TR (1988) Review of oceanic turbulence: implications for biodynamics. In: Rothschild BJ (ed) Toward a theory on biological-physical interactions in the world ocean. Kluwer Academic Publishers, Dordrecht, p 215-234

Yamazaki H, Osborn TR, Squires KD (1991) Direct numerical simulation of planktonic contact in turbulent flow. J Plankton Res 13:629-643

Submitted: April 3, 2000; Accepted: September 25, 2000 Proofs received from author(s): March 13, 2001 